\title{
Erratum to: Do bird spatial distribution patterns reflect population trends in changing landscapes?
}

\author{
Clélia Sirami • Lluis Brotons · Jean-Louis Martin
}

Published online: 29 October 2009

(C) Springer Science+Business Media B.V. 2009

\section{Erratum to: Landscape Ecol (2009) 24:893-906 DOI 10.1007/s10980-009-9365-5}

The authors regret that there was a mistake in Table 2 in the above paper. This mistake affects the results

The online version of the original article can be found under doi:10.1007/s10980-009-9365-5.

\section{Sirami · L. Brotons · J.-L. Martin ( $₫)$}

Centre d'écologie fonctionnelle et évolutive U.M.R. 5175, CNRS, 1919 route de Mende, 34293 Montpellier Cedex, France

e-mail: jean-louis.martin@cefe.cnrs.fr

C. Sirami

e-mail: cleliasirami@hotmail.com

C. Sirami

Climate Change \& Bioadaptation, South African National Biodiversity Institute, P/Bag x7, Claremont 7735,

Cape Town, South Africa

\section{Sirami}

Botany Department, University of Cape Town,

Private Bag, Rondebosch 7701, South Africa

L. Brotons

Centre Tecnològic Forestal de Catalunya, Area de Biodiversitat, Ctra. St. Llorenç km 2, 25280 Solsona, Spain

\section{J.-L. Martin}

Environment Canada, National Wildlife Research Centre, Carleton University, Ottawa, ON K1A 0H3, Canada presented in the paragraph Landscape changes but does not affect the general conclusion.

\section{Results}

Landscape changes

Open habitat was associated with a low overlap of polygons between years (RAO) and a high percentage of existing polygons that disappeared (RAD; Table 2). The number of Open habitat polygons decreased while the median of their size increased (Table 2) due to the disappearance of the smallest polygons (Fig. 2). Shrubland also showed a low overlap of polygons between years as well as a high percentage of both disappearance of existing polygons and generation of new polygons (Table 2). The number of Shrubland polygons increased and the median of their size decreased (Table 2) due to the fragmentation of existing polygons and the appearance of small polygons in former open habitat (Fig. 2). Woodland was characterised by a high percentage of overlap of polygons between years and a high percentage of generation of new polygons (Table 2). The number of Woodland polygons increased and the median of their size decreased (Table 2) due to the appearance of several small polygons (Fig. 2). At the same time, several Woodland polygons merged, resulting in the expansion of the main woodland polygon from 1442 ha in 1981 to 1805 ha in 2002. 
Table 2 Characteristics of the spatial distribution of the three main land cover categories in 1981, 1992 and 2002 (number of polygons and polygon size-median and range in hectares) and their dynamics over 1981-1992, 1992-2002 and 1981-2002

\begin{tabular}{|c|c|c|c|c|c|c|c|c|c|c|}
\hline & \multicolumn{3}{|c|}{ Polygon nb } & \multicolumn{3}{|l|}{ Polygon size (ha) } & & \multicolumn{3}{|c|}{ Polygon dynamics } \\
\hline & 1981 & 1992 & 2002 & 1981 & 1992 & 2002 & & RAD & RAO & RAG \\
\hline \multirow[t]{3}{*}{ Open habitat } & 80 & 78 & 74 & $1.03(0.06-92)$ & $0.92(0.06-41)$ & $1.27(0.06-41)$ & $81-92$ & 38 & 62 & 6 \\
\hline & & & & & & & $92-02$ & 3 & 97 & 17 \\
\hline & & & & & & & $81-02$ & 46 & 54 & 9 \\
\hline \multirow[t]{3}{*}{ Shrubland } & 32 & 69 & 88 & $1.90(0.16-465)$ & $1.03(0.01-526)$ & $0.84(0.07-444)$ & $81-92$ & 26 & 74 & 17 \\
\hline & & & & & & & $92-02$ & 30 & 70 & 8 \\
\hline & & & & & & & $81-02$ & 46 & 54 & 18 \\
\hline \multirow[t]{3}{*}{ Woodland } & 26 & 48 & 56 & $0.99(0.11-1442)$ & $0.69(0.03-1674)$ & $0.57(0.07-1805)$ & $81-92$ & 1 & 99 & 14 \\
\hline & & & & & & & $92-02$ & 1 & 99 & 11 \\
\hline & & & & & & & $81-02$ & 1 & 99 & 24 \\
\hline
\end{tabular}

$R A D$ relative area disappearance, $R A O$ relative area overlap, $R A G$ relative area generation corresponding to the percentage of the distribution, respectively disappearing, persisting or being generated (Cf. methods) 